\title{
Measurements of the Production and Transport of Helium Ash on the TFTR
}

\section{Tokamak}

E.J. Synakowski, R.E. Bell, R.V. Budny, C.E. Bush, (a) P.C. Efthimion, B. Grek,

D.W. Johnson, L.C. Johnson, B. LeBlanc, H. Park, G. Taylor

Princeton Plasma Physics Laboratory, P.O. Box 45i, Princeton, New Jersey USA 08543

Helium ash production and transport have been measured in TFTR deuterium-tritium plasmas using charge-exchange recombination spectroscopy. The helium ash confinement time, including recycling effects, is 6-10 times the energy confinement time and is compatible with sustained ignition in a reactor. The ash confinement time is dominated by edge pumping rates rather than core transport. The measured evolution of the local thermal ash density agrees with modelling, indicating that alpha particle slowing-down calculations used in the modelling are reasonable.

PACS numbers: 52.55.Pi, 52.25.Fi, 52.25.Vy

\section{DISCLAIMER}

\begin{abstract}
This report was prepared as an account of work sponsored by an agency of the United States Government. Neither the United States Government nor any agency thereof, nor any of their employees, makes any warranty, express or implied, or assumes any legal liability or responsiprocess disclosed, ory, completeness, or usefulness of any information, apparatus, product, or process disclosed, or represents that its use would not infringe privately owned rights. Refermanufacturer, ar specific commercial product, process, or service by trade name, trademark, manufacturer, or otherwise does not necessarily constitute or imply its endorsement, recomand opinions favoring by the United States Government or any agency thereof. The views and opinions of authors expressed herein do not necessarily state or reflect those of the United States Government or any agency thereof.
\end{abstract}

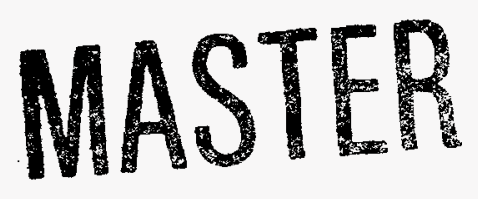


Helium ash production, transport, and removal will play a decisive role in determining the cost and the viability of a deuterium-tritium fusion reactor based on magnetic confinement schemes. Studies ${ }^{1-5}$ indicate that ash concentration, and ultimately its reduction, in a future reactor will depend critically on the relationship between energy transport and helium particle transport in the plasma core, as well as particle reflux properties at the plasma boundary. If transport of helium ash from the core to the edge is slow compared to its production rate, the ash may quench the burn before any significant pumping can take place. Moreover, even if the core helium transport is rapid, inefficient edge pumping or reduced edge transport might lead to intolerably high central ash densities.

Deuterium-tritium (DT) operation on TFTR 6.7 provides the first opportunity to observe the production of helium ash and its transport. Although the fusion power in these plasmas $(\sim 5 \mathrm{MW})$ is modest by reactor standards, the on-axis helium ash source strength is comparable to that expected for ITER. Also, while a reactor-relevant helium pumping scheme needs to be developed, the TFTR bumper limiter pumps helium and other noble gases. ${ }^{8}$ These facts enable the study of a prototypical reactor with all the essential elements as they pertain to ash birth, transport, and removal. As such, DT operation allows testing of expectations from earlier helium transport experiments. Using gas puffing $9,10,11$ and helium beam injection, 12 these studies have generally concluded that core helium transport should be fast enough to remove helium ash from the plasma center, before significant accumulation can occur, and deposit it in the plasma periphery, where it might be pumped.

Presented in this report are the first measurements of the transport of helium ash born in a deuterium-tritium tokamak plasma. Pairs of similar deuterium-only (DD) and deuterium-tritium (DT) plasmas were investigated. The measurements were made using charge-exchange recombination spectroscopy (CHERS). ${ }^{13}$ The thermal helium density $n_{\mathrm{He}}$ was inferred by observing Dopplerbroadened emission from the $4686 \AA, n=4-3 \mathrm{He}^{+}$line, excited by charge exchange between deuterium heating beam neutrals and $\mathrm{He}^{2+}$. These measurements present a challenge for several reasons. First, helium is present in all TFTR plasmas to some degree. Typical helium concentrations are about $0.2-0.3 \%$ of the electron density during the neutral beam heating phase, yet the maximum ash concentration expected in high-power DT plasmas is about $0.2 \%$, implying that the desired signal will rest on top of a large background. Also, bright emission of the same line from the cooler 


\section{DISCLAIMER}

Portions of this document may be illegible in electronic image products. Images are produced from the best available original document. 
plasma periphery accompanies the beam-induced portion of the spectrum and rivals the latter part in total brightness.

An array of fiber optics views three of the heating beam sources on the plasma midplane. The sightlines cross the beams with a radial separation of $6 \mathrm{~cm}$ and span the plasma outside the magnetic axis. The integration time of the CHERS diagnostic was $0.1 \mathrm{~s}$. The plasmas had a major radius of $2.52 \mathrm{~m}$, a minor radius of $0.87 \mathrm{~m}$, and a plasma current of $2.0 \mathrm{MA}$. For the DD and DT case, approximately 21 - $22 \mathrm{MW}$ of nearly balanced neutral beam power was injected from $2.8 \mathrm{~s}$ to $4.1 \mathrm{~s}$ into a deuterium target plasma. For both plasmas, deuterium-only injection at lower power (12 MW) followed this phase, ending at $4.8 \mathrm{~s}$. The measured neutron emission and the calculated volumeintegrated helium source due to the thermalization of alpha particles are shown in Fig. 1 for the DT plasma. The fusion power during the neutron flattop was about 4.5 MW. The central ion temperature $\mathrm{T}_{\mathrm{i}}(0)$ during the high-power phase of similar plasmas was $25 \mathrm{keV}$, dropping to $18 \mathrm{keV}$ during the 12 MW phase. The $T_{i}$ profile was measured viewing the $5292 \AA$ line of $\mathrm{C}^{5+}$, induced by charge exchange between beam neutrals and $\mathrm{C}^{6+}$. The central electron temperature $\mathrm{T}_{e}(0)$, measured with a Michelson interferometer, was $9 \mathrm{keV}$ in the high power phase of both plasmas, and dropped to 7 $\mathrm{keV}$ in the latter phase. The central electron density was $6.7-7 \times 10^{19} \mathrm{~m}^{-3}$ in the high power phase of each discharge, falling to $4.5 \times 10^{19} \mathrm{~m}^{-3}$ in the $12 \mathrm{MW}$ portion. The central $Z_{\text {eff, inferred from }}$ visible bremsstrahlung measurements, was 3 in the high power phase, dropping to 2.4 in the low power phase. The enhancement factor over L Mode energy confinement time values was 1.9 during high-power injection, and 1.4 in the latter phase. Sawteeth were absent from the DT discharge until $4.78 \mathrm{~s}, 20 \mathrm{~ms}$ prior to the end of neutral beam injection, and were absent from the DD discharge. The DT plasma also had fishbone activity throughout most of the neutral beam heating phase. Fiber transmission dropped transiently by $9 \%$ during tritium injection due to high neutron and gamma fluxes. ${ }^{14}$ Its time-dependence was measured directly with a calibration loop, 15 and the effect was taken into account in this experiment.

Modelling indicates that the slowing-down time of the alpha particles should be $0.5-0.7 \mathrm{~s}$, and that ash should appear in the core throughout the deuterium-only phase of injection. The ash source was calculated with the TRANSP code; 16 using measured plasma profiles, calculated beam 
deposition, and calculations of the alpha particle source and transport. Neutron emissivity profiles, measured by a neutron collimator diagnostic, 17,18 agree with modelled profile shapes and amplitudes. The profiles are strongly peaked, and have a HWHM of about $20 \%$ of the minor radius of the plasma. The alpha particles are assumed to transport classically until their energy is equal to $3 / 2$ the local ion temperature. Below this energy, the alpha particles (now helium ash) are subject to prescribed transport coefficients. Modelling indicates that the energetic alpha particle transport should be modest, and that the helium ash thermalization profile should have the same shape as that of the neutrons. Single-point measurements of the central alpha particle density and energy distribution between $100-600 \mathrm{keV}$, measured with the alpha-CHERS diagnostic, 19 are consistent with modelling predictions of good confinement of the alpha particles. The measured energy distribution of the alphas between $250 \mathrm{keV}$ and $2 \mathrm{MeV}$, made by examining charge exchange products following lithium pellet injection in other DT plasmas, is also consistent with classical transport. ${ }^{20}$ Also, probe measurements indicate fast alpha particle losses are small in a wide range of DT plasmas. ${ }^{21}$ The transport coefficients for the thermalized ash were determined by helium gas puffing in a 1 MA plasma previously described. ${ }^{12}$ The helium diffusivity, $\mathrm{D}_{\mathrm{He}}$, is on the order of the effective thermal conductivity, $\chi$ eff, throughout the plasma cross section, while the convective pinch, $\mathrm{V}_{\mathrm{He}}$, is inward and on the order of $-1 \mathrm{~m} / \mathrm{s}$ near the axis, near zero at $\mathrm{r} / \mathrm{a}=0.5$, and $\sim-5 \mathrm{~m} / \mathrm{s}$ near the plasma periphery.

Late in time, a distinct increase in the brightness of the thermal portion of the CHERS spectrum is found in the DT plasmas as compared to their DD counterparts, corresponding to a local increase in the helium density in DT as compared to DD. Spectra from a sightline passing through the neutral beam at $\mathrm{r} / \mathrm{a}=0.45$ are shown in Fig. 2 for two plasma pairs. The first (Fig. 2(a) and 2(b)) is a DTDD pair at nearly the same powers ( 22 and $21 \mathrm{MW}$, respectively, in the high power phase), and the second is another pair of matched DD-only plasmas (27 MW in the high power phase; Fig. 2(c) and 2(d)). At $3.45 s$, before alpha particles are expected to be thermalized, the helium spectra for a given sightline are indistinguishable. However, at $4.75 \mathrm{~s}$, an increase in the total helium line brightness is found in the DT plasma as compared to the DD case. This difference is seen on all spatial channels, and in other DT-DD shot pairs. The edge ion temperature and electron density typically varies by less 
than $5 \%$ in the DT-DD and DD-DD pairs, indicating that changes in helium influx from the wall are not likely causes of the difference in the overall helium density.

Determination of the ash density requires separation of the beam-induced portion of the signal from emission from the plasma periphery. For profile measurements at the end of the neutral beam phase, the spectrum measured just after beam turn-off was subtracted from that measured just prior to beam turn-off. A correction of about $10 \%$ in the helium edge brightness, resulting from the decay of the emission following beam turn-off, was applied. It was determined by observing the edge emission behavior with high time resolution ( $10 \mathrm{~ms})$. Because different combinations of gaussians often yield equally plausible fits, the beam-induced portion of the total line brightness was extracted by modelling the time behavior of the brightness of the edge emission. 22 Plume emission ${ }^{23}$ was separated from the charge-exchange component by solving for the total brightness with a selfconsistent model that iterates an assumed helium profile shape until agreement with the measured total radial brightness profile is reached. The plume can approach the charge exchange component in total brightness, but is common to both plasmas. The CHERS system was calibrated by introducing a small helium gas puff to similar DD discharges. The total electron number rise following the puff was measured, and the change was attributed entirely to helium. Calibration in this manner yields a system response function that includes the effects of both plume and prompt emission.

The radial helium ash profile shape and total particle number late in time indicates that the ash transports rapidly from the central source region to the plasma periphery, where it is pumped. Measured and modelled profiles are shown in Fig. 3(a) for $4.75 \mathrm{~s}$. The ash profile is inferred from the difference in the local helium densities measured in the DT and DD shot. The measured profile shape is broad, in agreement with the modelling. The measured total ash particle number agrees with the TRANSP simulations only if the recycling coefficient $R_{H e}$ is below unity. A value of 0.85 was used since it reproduces helium decay times following a short gas puff in plasmas with similar working gas wall pumping characteristics. Under the assumption of zero radial transport (perfect confinement), the modelled profile shape is much more peaked than that measured, and yields a central helium density and a total helium particle number that is larger by a factor of two. 
The total helium ash residence time in the vacuum vessel, $\tau_{\mathrm{He}}^{*}$, is $1.2 \pm 0.3 \mathrm{~s}$, about $(6-10) \tau_{\mathrm{E}}$, and consistent with the requirements for a sustained fusion burn in a reactor. ${ }^{3}$ Here, $\tau_{E}$ is the global energy confinement time. The residence time was determined from the continuity equation, $\mathrm{dN} \mathrm{Ne}_{\mathrm{He}} / \mathrm{dt}$ $=-\mathrm{N}_{\mathrm{He}} / \tau_{\mathrm{He}}^{*}+S_{\mathrm{He}}$, where $\mathrm{N}_{\mathrm{He}}$ is the measured total helium ash particle number and $S_{\mathrm{He}}$ is the calculated volume-integrated alpha particle thermalization (central ash source) rate. This value of $\tau_{\mathrm{He}}^{*}$ agrees with that deduced independently from helium gas puffing. However, the helium particle confinement time $\tau_{\mathrm{He}}$ (which does not include recycling effects), obtained with the calculated central ash source profile and the measured $D_{\mathrm{He}}$ and $\mathrm{V}_{\mathrm{He}}$, is about $0.3 \mathrm{~s}$, or $2 \tau_{\mathrm{E}}$. Therefore, edge reflux, and not core transport, will be the limiting factor determining helium removal from a reactor-grade plasma with core transport mechanisms similar to TFTR supershots. The dominance of the edge source over the central source late in time is illustrated in Fig. 3(b). That $\tau_{\mathrm{He}}$ is larger than but on the order of $\tau_{\mathrm{E}}$ is born from the similarity between $D_{\mathrm{He}}$ and $\chi_{\mathrm{eff}}$, the fact that the central helium ash source is somewhat more peaked that the heating source, and the influence of $\mathrm{V}_{\mathrm{He}}$ at the edge of the plasma.

Finally, the agreement between the measured and modelled helium ash time evolution indicates that the alpha particle slowing-down calculations are reasonable. Shown in Fig. 4(a) and 4(c) is the beam-induced helium line brightness (prompt charge exchange emission, plus plume emission) for sightlines passing through the beams at $r / a=0.24$ and at $r / a=0.8$. In Fig. $4(b)$ and $4(d)$, the difference in the inferred local helium density between the DT and the DD plasmas is shown, including the effects of time-varying beam attenuation. The attenuation changes are common to both plasmas, and thus the relative increase in the brightness in the DT plasma is a signature of a local helium density increase. Best agreement between the modelling and the measurement is obtained using the measured values of $\mathrm{D}_{\mathrm{He}}$ and $\mathrm{V}_{\mathrm{He}}$. If the assumed transport coefficients are reduced, the density increase near the axis at the end of injection is expected to be larger than that measured at the end of neutral beam injection, owing to the longer core ash confinement time in this case. If the transport is assumed to be faster than that measured from the gas puffs, ash particles are expected to be lost from the plasma more quickly than observed, resulting in lower core densities. 
In summary, helium ash has been measured in TFTR DT discharges. The limiting factor determining steady-state ash densities in a reactor-grade plasma is likely to be edge helium reflux rather than core transport if the basic transport mechanisms are similar to those in TFTR supershots. Also, the time scale of the appearance of alpha particles as ash is consistent with modelling results.

It is a pleasure to acknowledge the support of the TFTR physicists, engineers, technical staff, and computer operators. This research was conducted under DOE Grant No. DE-AC02-76-CHO3703.

(a)Permanent address: Oak Ridge National Laboratory, Oak Ridge, Tennessee 37830

1 F. Engelmann, Comments Plasma Phys. Controll. Fusion 5261 (1980).

2 R.J. Taylor, B.D. Fried, and G.J. Marales, Comments Plasma Phys. Controlled Fusion 13,227 (1990).

3 D. Reiter, G.H. Wolf, and H. Kever, Nucl. Fusion 302141 (1990).

4 M.H. Redi and S.A. Cohen, Fusion Technol. 2048 (1991).

5 M.H. Redi, S.A. Cohen, and E.J. Synakowski, Nucl. Fusion 311689 (1991).

6 R.J. Hawryluk et al., Phys. Rev. Lett. 72, 3530 (1994).

7 J.D Strachan et al., Phys. Rev. Lett. 72, 3526 (1994).

8 A.T. Ramsey and D.M. Manos, J. Nucl. Matl. 196-198, 509 (1992).

9 E.J. Synakowski et al., Phys. Rev. Lett. 65, 2255 (1990).

10 D.L. Hillis et al., Phys. Rev. Lett. 65, 2382 (1990).

11 E.J. Synakowski et al., Phys. Fluids B 5, 2215 (1993).

${ }^{12}$ H. Nakamura et al., Phys. Rev. Lett. 67, 2658 (1991).

13 B.C. Stratton et al., in Proceedings of the IAEA Technical Committee Meeting on Time Resolved Two- and Three-Dimensional Plasma Diagnostics, Nagoya, Japan (International Atomic Energy Agency, Vienna, 1991), p. 78.

14 A.T. Ramsey, Rev. Sci. Instrum. 66, 871 (1995).

15 C.E. Bush, R.E. Bell, and E.J. Synakowski, Rev. Sci. Instrum. 66, 642 (1995).

16 R. Budny et al., Nucl. Fusion 32, 429 (1992). 
17 L.C. Johnson, Rev. Sci. Instrum. 63, 4517 (1992)

18 A.L. Roquemore, R.C. Chouinard, M. Diesso, et al., Rev. Sci. Instrum. 61, 3163 (1990).

19 G. McKee, to be submitted to Phys. Rev. Lett.

20 R. Fisher, to be submitted to Phys. Rev. Lett.

21 S.J. Zweben, Princeton Plasma Physics Laboratory Report PPPL-3045, submitted to Nucl.

Fusion.

22 E.J. Synakowski, R.E. Bell, and C.E. Bush, Rev. Sci. Instrum. 66649 (1995).

23 R.J. Fonck, D.S. Darrow, and K.P. Jaehnig, Phys. Rev. A 29, 3288 (1984).

8 
FIG. 1. The measured total neutron rate and the calculated total alpha particle thermalization rate for the DT plasma. The shaded regions indicate the relative powers and durations of the two neutral beam heating phases.

FIG. 2. $\mathrm{He}^{+}$spectra $(n=4-3,4686 \AA)$ from a sightline passing through the neutral beam at $\mathrm{r} / \mathrm{a}=$ 0.45 for $(a, b)$ a DT-DD plasma pairs and (c,d) a DD-DD plasma pair. At $3.45 \mathrm{~s}$, the DD-DD pair had $27 \mathrm{MW}$ of neutral beam injection, and the DT-DD pair had $22 \mathrm{MW}$. Both had $12 \mathrm{MW}$ of Donly injection between 4.1 and $4.8 \mathrm{~s}$. In (d), typical edge emission immediately after injection is shown.

FIG. 3. (a). Measured and modelled ash profile shapes just prior to the end of beam injection. The individual profile uncertainties (from plume corrections, beam attenuation and background emission subtraction) were propagated in estimating the errors of this difference profile. (b). Modelled total helium ash source profiles.

FIG. 4. (a). Beam-induced helium line brightness for (a) $r / a=0.24$. (b). The difference in the local helium density between the two discharges at $\mathrm{r} / \mathrm{a}=0.24$, and TRANSP model predictions of the density evolution. The multipliers refer to variations in the assumed values of $\mathrm{DHe}_{\mathrm{He}}$ and $\mathrm{Ve}$ from the experimental values. (c). Same as (a), but for $r / a=0.8$. (d). Same as (b), but for $\mathrm{r} / \mathrm{a}=$ 0.8 . 


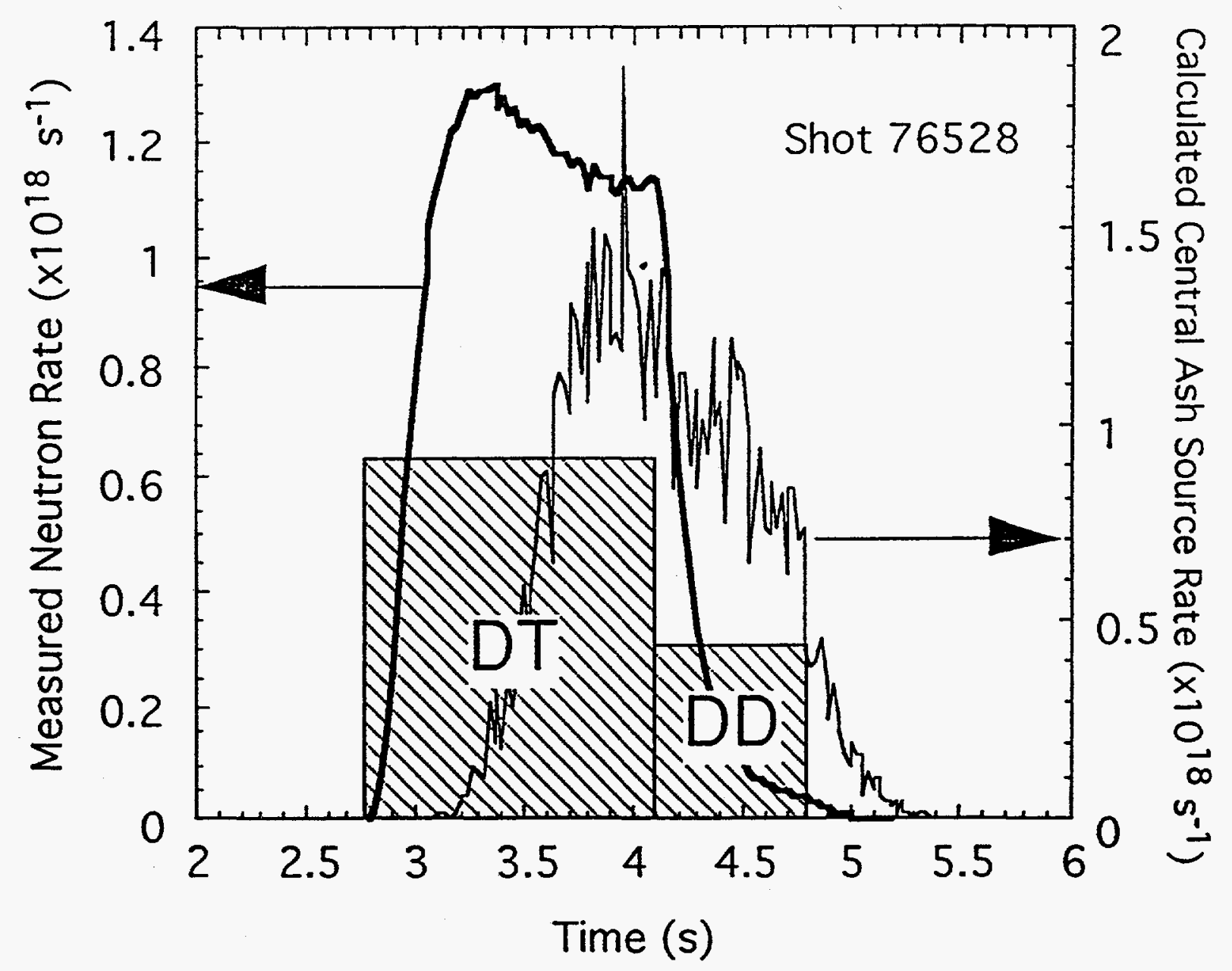

Figure 1 
$\frac{T}{0}$
$\frac{0}{5}$
0
$N$

Brightness (a.u.)

Brightness (a.u.)
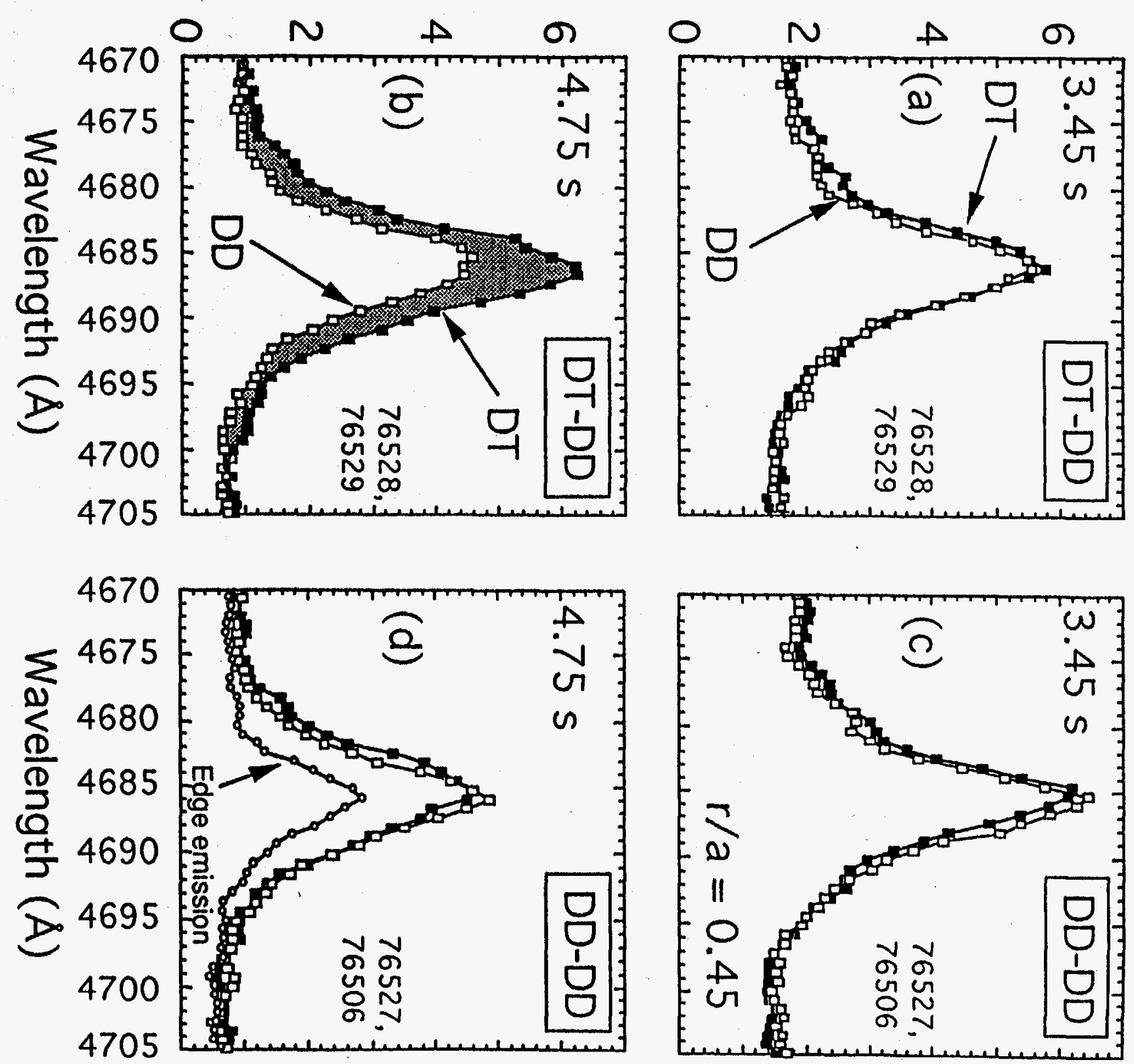

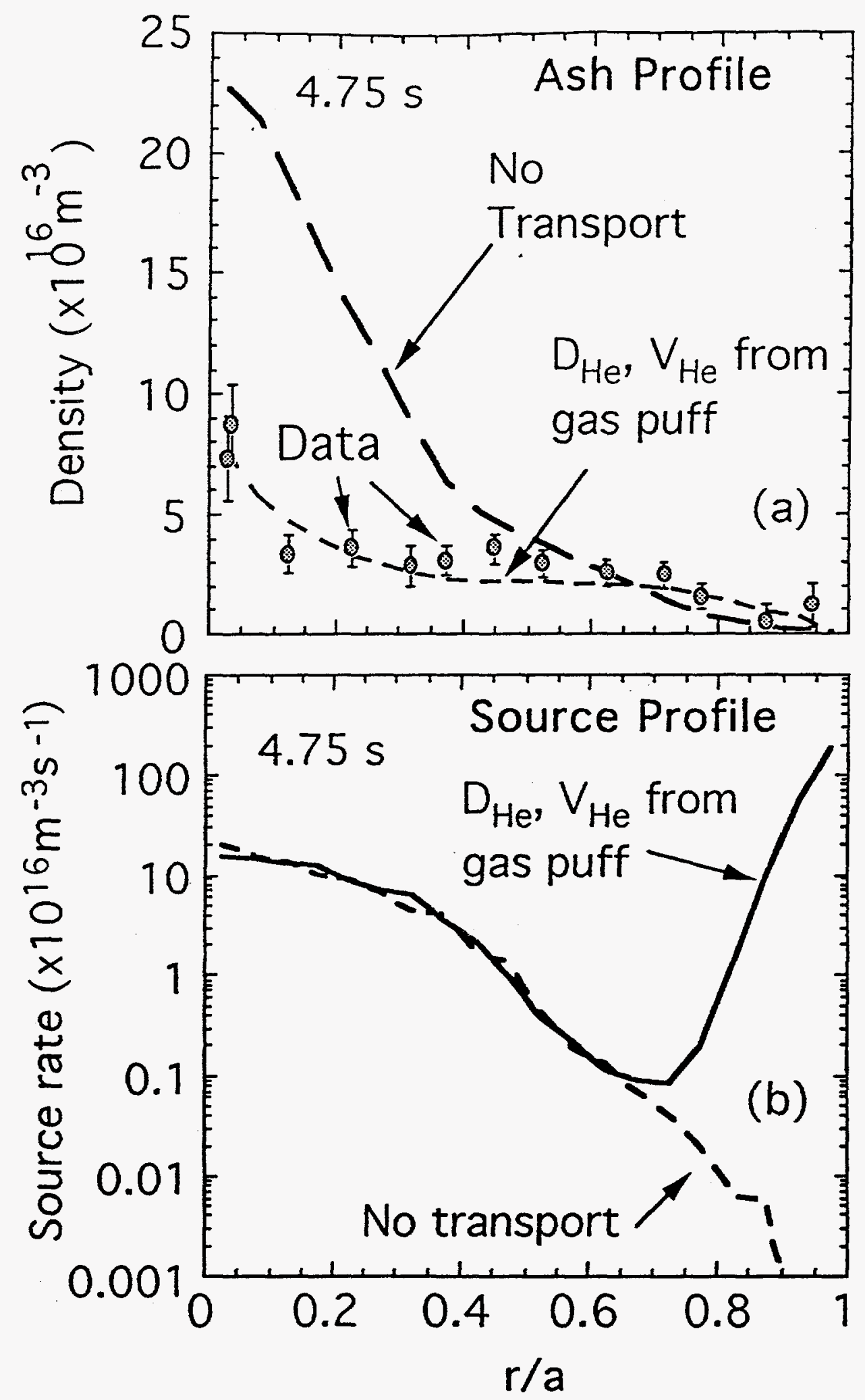

Figure 3 

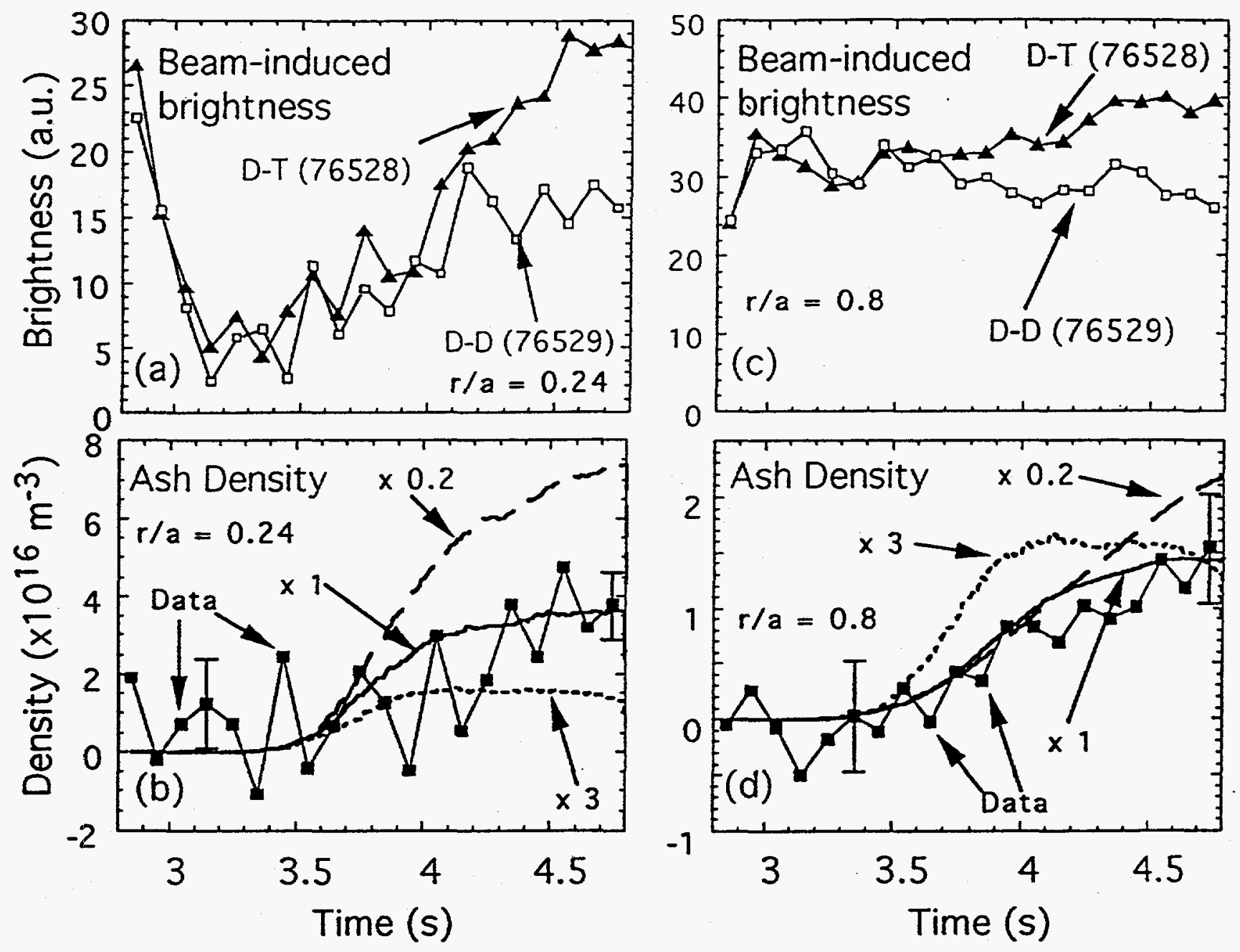

Figure 4 
Dr. F. Paoloni, Univ. of Wollongong, AUSTRALIA

Prof. R.C. Cross, Univ. of Sydney, AUSTRALIA

Plasma Research Lab., Australian Nat Univ., AUSTRALIA

Prof. I.R. Jones, Flinders Univ, AUSTRALIA

Prof. F. Cap, Inst. for Theoretical Physics, AUSTRIA

Prof. M. Heindler, Institut für Theoretische Physik, AUSTRIA

Prof. M. Goossens, Astronomisch Instituut, BELGIUM

Ecole Royale Militaire, Lab. de Phy. Plasmas, BELGIUM

Commission-European, DG. XII-Fusion Prog., BELGIUM

Prof. R. Bouciqué, Rijksuniversiteit Gent, BELGIUM

Dr. P.H. Sakanaka, Instituto Fisica, BRAZIL

Prof. Dr. I.C. Nascimento, Instituto Fisica, Sao Paulo, BRAZIL Instituto Nacional De Pesquisas Espaciais-INPE, BRAZIL Documents Office, Atomic Energy of Canada Ltd., CANADA Ms. M. Morin, CCFMTokamak de Varennes, CANADA Dr. M.P. Bachynski, MPB Technologies, Inc., CANADA Dr. H.M. Skarsgard, Univ. of Saskatchewan, CANADA Prof. J. Teichmann, Univ. of Montreal, CANADA

Prof. S.R. Sreenivasan, Univ. of Calgary, CANADA

Prof. T.W. Johnston, INRS-Energie, CANADA

Dr. R. Bolton, Centre canadien de fusion magnétique, CANADA

Dr. C.R. James, Univ, of Alberta, CANADA

Dr. P. Lukác, Komenského Universzita, CZECHO-SLOVAKIA

The Librarian, Culham Laboratory, ENGLAND

Library, R61, Rutherford Appleton Laboratory, ENGLAND

Mrs. S.A. Hutchinson, JET Library, ENGLAND

Dr. S.C. Shama, Univ. of South Pacific, FIJI ISLANDS

P. Măhönen, Univ. of Helsinki, FINLAND

Prof. M.N. Bussac, Ecole Polytechnique, FRANCE

C. Mouttet, Lab. de Physique des Milieux lonisés, FRANCE

J. Radot, CEN/CADARACHE - Bat 506, FRANCE

Prot. E. Economou, Univ. of Crete, GREECE

Ms. C. Rinni, Univ. of loannina, GREECE

Preprint Library, Hungarian Academy of Sci., HUNGARY

Dr. B. DasGupta, Saha inst. of Nuclear Physics, INDIA

Dr. P. Kaw, Inst. for Plasma Research, INDIA

Dr. P. Rosenau, lsrael inst. of Technology, ISRAEL Librarian, Intemational Center for Theo Physics, ITALY Miss C. De Palo, Associazione EURATOM-ENEA, ITALY Dr. G. Grosso, Istituto di Fisica del Plasma, ITALY

Prol. G. Postangni, Istituto Gas lonizzati Del Cnr, ITALY
Dr. H. Yamato, Toshiba Res \& Devel Center, JAPAN

Prof. I. Kawakami, Hiroshima Univ., JAPAN

Prof. K. Nishikawa, Hiroshima Univ., JAPAN

Librarian, Naka Fusion Research Establishment, JAERI, JAPAN

Director, Japan Atomic Energy Research inst., JAPAN

Prof. S. Itoh, Kyushu Univ., JAPAN

Research Info. Ctr., National Instit. tor Fusion Science, JAPAN

Prot. S. Tanaka, Kyoto Univ., JAPAN

Librany, Kyoto Univ., JAPAN

Prof. N. Inove, Univ. of Tokyo, JAPAN

Secretary, Plasma Section, Electrotechnical Lab., JAPAN

Dr. O. Mitarai, Kumamoto Inst. of Technology, JAPAN

Dr. G.S. Lee, Korea Basic Sci. Ctr., KOREA

J. Hyeon-Sook, Korea Atomic Energy Research Inst., KOREA

D.I. Choi, The Korea Adv. Inst. of Sci. \& Tech., KOREA

Prof. B.S. Liley, Univ. of Waikato, NEW ZEALAND Inst of Physics, Chinese Acad Sci PEOPLE'S REP. OF CHINA Library, Inst. of Plasma Physics, PEOPLE'S REP. OF CHINA Tsinghua Univ. Library, PEOPLE'S REPUBLIC OF CHINA Z. Li, S.W. Inst Physics, PEOPLE'S REPUBLIC OF CHINA Prof. J.A.C. Cabral, Instituto Superior Tecnico, PORTUGAL Prot. M.A. Hellberg, Univ. of Natal, S. AFRICA Prof. D.E. Kim, Pohang Inst. of Sci. \& Tech., SO. KOREA Prof. C.I.E.M.A.T, Fusion Division Library, SPAIN

Dr. L. Stenflo, Univ. of UMEA, SWEDEN

Library, Royal Inst. of Technology, SWEDEN

Prol. H. Wilhelmson, Chalmers Univ. of Tech., SWEDEN Centre Phys. Des Plasmas, Ecole Polytech, SWITZERLAND Bibliotheek, Inst. Voor Plasma-Fysica, THE NETHERLANDS Asst. Prof. Dr. S. Cakir, Middle East Tech. Univ., TURKEY Dr. V.A. Glukhikh,Sci. Res. Inst. Electrophys.I Apparatus, USSR Dr. D.D. Ayutov, Siberian Branch of Academy of Sa., USSR Dr. G.A. Eliseev, I.V. Kurchatov Inst, USSR Librarian, The Ukr.SSR Academy of Sciences, USSR Dr. LM. Kovrizhnykh, Inst. of General Physics, USSR Kemforschungsanlage GmbH, Zentralbibliothek, W. GERMANY Bibliothek, inst. Fü Plasmaforschung, W. GERMANY Prof. K. Schindler, Ruhr-Universitát Bochum, W. GERMANY Dr. F. Wagner, (ASDEX), Max-Planck-Institut, W. GERMANY Librarian, Max-Planck-Institut, W. GERMANY 